\section{(2) OPEN ACCESS}

\title{
Eosinophilic inflammation in COPD: from an inflammatory marker to a treatable trait
}

\author{
Benjamin David, ${ }^{1}$ Mona Bafadhel 0 (, ${ }^{2}$ Leo Koenderman, ${ }^{3}$ Antony De Soyza ${ }^{4}$
}

\begin{abstract}
- Additional material is published online only. To view, please visit the journal online (http://dx.doi.org/10.1136/ thoraxjnl-2020-215167).
\end{abstract}

${ }^{1}$ Research \& Development, GlaxoSmithKline plc, Middlesex, UK

${ }^{2}$ Nuffield Department of Medicine, University of Oxford, Oxford, UK

${ }^{3}$ Department of Respiratory Medicine and Center for Translational Immunology (CTI), University Medical Center Utrecht, Utrecht, The Netherlands

${ }^{4}$ Institute of Cellular Medicine, NIHR Biomedical Research Centre for Aging and Department of Respiratory Medicine, Newcastle upon Tyne NHS Foundation Trust, Newcastle upon Tyne, UK

\section{Correspondence to}

Dr Antony De Soyza, Newcastle upon Tyne Hospitals Trust, Newcastle upon Tyne, UK; anthony.de-soyza@newcastle. ac.uk

Received 29 April 2020 Revised 28 July 2020 Accepted 1 October 2020

Published Online First 29 October 2020

\section{Check for updates}

(C) Author(s) (or their employer(s)) 2021. Re-use permitted under CC BY-NC. No commercial re-use. See rights and permissions. Published by BMJ.

To cite: David B, Bafadhel $M$ Koenderman $L$, et al. Thorax 2021;76:188-195.

\section{ABSTRACT}

The heterogeneity of chronic obstructive pulmonary disease (COPD) creates many diagnostic, prognostic, treatment and management challenges, as the pathogenesis of COPD is highly complex and the underlying cellular and molecular mechanisms remain poorly understood. A reliable, easy-to-measure, clinically relevant biomarker would be invaluable for improving outcomes for patients. International and national guidance for COPD suggests using blood eosinophil counts as a biomarker to help estimate likely responsiveness to inhaled corticosteroids (ICS) and, potentially, to aid effective management strategies. However, with the mechanism underlying the association between higher eosinophil levels and ICS effect unknown, use of the blood eosinophil count in COPD continues to be widely debated by the respiratory community.

Two international meetings involving respiratory medicine specialists, immunologists and primary and secondary care clinicians were held in November 2018 and March 2019, facilitated and funded by GlaxoSmithKline plc. The aims of these meetings were to explore the role of eosinophils in the disease processes of COPD and as prognostic and diagnostic markers, and to identify areas of deficient knowledge that warrant further research. The consensus views of the attendees on key topics, contextualised with current literature, are summarised in this review article, with the aim of aiding ongoing research into the disease processes of COPD and the development of biomarkers to aid clinical management.

Under certain conditions, eosinophils can be recruited to the lung, and increasing evidence supports a role for eosinophilic inflammation in some patients with COPD. Infiltration of eosinophils across the bronchial vascular epithelium into the airways is promoted by the actions of immunoregulatory cells, cytokines and chemokines, where eosinophil-mediated inflammation is driven by the release of proinflammatory mediators.

Multiple studies and two meta-analyses suggest peripheral blood eosinophils may correlate positively with an increased likelihood of exacerbation reduction benefits of ICS in COPD. The studies, however, vary in design and duration and by which eosinophil levels are viewed as predictive of an ICS response. Generally, the response was seen when eosinophil levels were 100-300 cells/ $\mu$ (or higher), levels which are traditionally viewed within the normal range. Some success with interleukin-5-targeted therapy suggests that the eosinophilic phenotype may be a treatable trait. The use of biomarkers could help to stratify treatment for COPD - the goal of which is to improve patient outcomes. Some evidence supports eosinophils as a potential biomarker of a treatable trait in COPD, though it is still lacking and research is ongoing. A unified consensus and a practical, accessible and affordable method of utilising any biomarker for COPD was thought to be of most importance. Challenges around its utilisation may include presenting a clear and pragmatic rationale for biomarker-driven therapy, guidance on ICS withdrawal between primary and secondary care and a lack of financial incentives supporting broad application in clinical practice. Future treatments should, perhaps, be more targeted rather than assuming the primary disease label (COPD or asthma) will define treatment response.

\section{INTRODUCTION}

Chronic obstructive pulmonary disease (COPD) is an umbrella term for a variety of lung conditions that the Global Initiative for Chronic Obstructive Lung Disease (GOLD) 2020 recommendations define as: 'a common, preventable and treatable disease that is characterised by persistent respiratory symptoms and airflow limitation that is due to airway and/or alveolar abnormalities usually caused by significant exposure to noxious particles or gases'. ${ }^{1}$ For reasons that are unclear, inflammation is no longer part of the GOLD definition of COPD; however, GOLD has introduced the blood eosinophil count as a biomarker for estimating the efficacy of inhaled corticosteroids (ICS) for the prevention of exacerbations. ${ }^{1}$ GOLD advises that a threshold of $\geq 100$ cells $/ \mu \mathrm{L}$ should be considered for ICS treatment in patients with COPD experiencing one exacerbation despite long-acting muscarinic

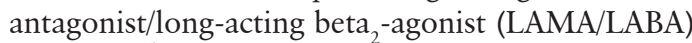
treatment. ${ }^{1}$ Although the benefits of ICS have been found to outweigh the risks, it is important to be mindful of these risks, particularly with respect to pneumonia. $^{23}$

The pathogenesis of COPD is highly complex and the underlying cellular and molecular mechanisms remain poorly understood. ${ }^{4}$ GOLD ${ }^{1}$ identifies three main mechanisms underlying COPD pathology: small airway disorders/abnormalities, emphysema and systemic effects. Additionally, Turner et $a l^{5}$ describe a larger series of clinically relevant characteristics in COPD; these include conditions (frequent exacerbator; chronic bronchitis; alpha-1 antitrypsin deficiency (A1ATD); upper zone dominant emphysema and bullous emphysema; type 1 respiratory failure; type 2 respiratory failure; eosinophilic COPD; and biomass COPD) with clear implications for treatment strategy, and conditions (pulmonary hypertension; bronchiectasis; systemic inflammation; and bacterial colonisation) that have implications for prognosis but where the therapeutic approach is less clear. Some phenotypes demonstrate discrete biochemical and clinical profiles. 


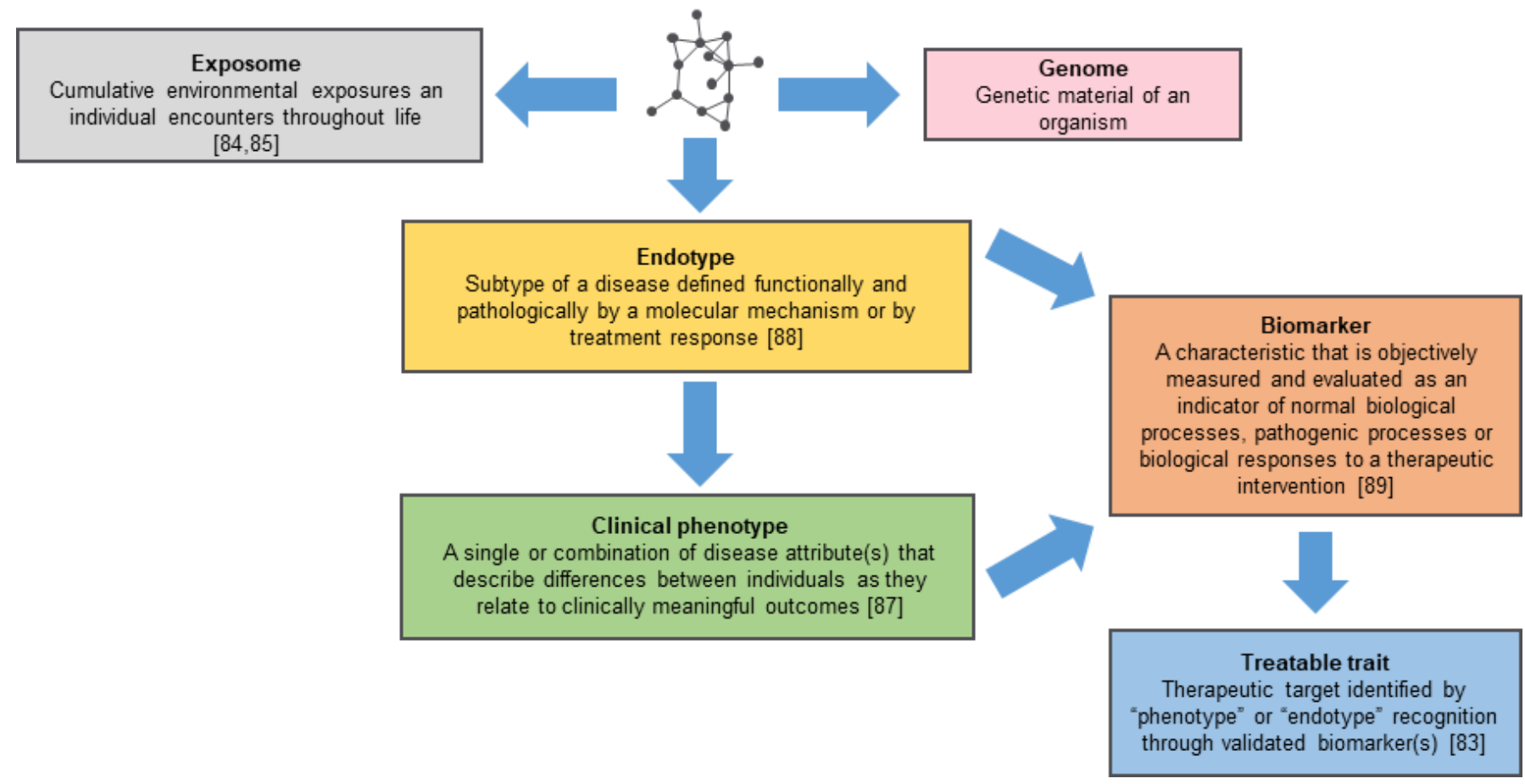

Figure 1 Relationships between the exposome and the genome, the emergence of endotypes and phenotypes and the possibility of identifying them through validated biomarkers of treatable traits. Redrawn with permission from 'Precision medicine in airway diseases: moving to clinical practice,' by Agusti, Bafadhel M, Beasley R, et al. Eur Respir J 2017;50(4):1701655, 2017 European Respiratory Society ${ }^{82-89}$

The limitations of using diagnostic labels such as 'COPD' or 'asthma', however, are becoming increasingly apparent; Agusti et $a l^{6}$ proposed a precision medicine strategy based on the presence (or absence) of 'treatable traits'. These traits may be based on 'phenotypic' recognition or on knowledge of the underlying pathways (eg, 'endotypes'). ${ }^{6}$ Rather than treating a patient diagnostically labelled with COPD or asthma, precision medicine treats a patient with airway disease based on the treatable traits present (figure 1). Agusti et al ${ }^{6}$ highlighted three sets of treatable traits in airway disease: pulmonary treatable traits (eg, eosinophilic airway inflammation), extrapulmonary traits (eg, cardiovascular disease) and treatable behaviour/lifestyle risk factors of airway diseases (eg, exposure to sensitising agents/pollution). ${ }^{6}$

A predominant characteristic of COPD is neutrophilic inflammation, ${ }^{4}$ with a subset of patients $(20 \%-40 \%)$ demonstrating an eosinophilic phenotype..$^{7-10}$ The latter is associated with a pattern of expression of type- 2 mediators in the airways, as can also be seen in patients with asthma. ${ }^{11}$ There may even be combined neutrophil/eosinophil phenotypes with varying degrees of each type of inflammation. Bafadhel et $a l^{12}$ (online supplemental table 1) demonstrated that the profile of airway inflammatory mediators in COPD and asthma are broadly similar, and that differences observed between eosinophilic and non-eosinophilic phenotypes are independent of disease. These data further highlight the limitations of using diagnostic labels.

The heterogeneity of COPD poses many diagnostic, prognostic and management challenges (box 1). Reliable, easily measurable, clinically relevant biomarkers to identify a COPD phenotype would be invaluable for improving patient outcomes. Recent guidance on the management of COPD $^{1}$ suggest using the blood eosinophil count as part of follow-up management in patients with a blood eosinophil count of $\geq 100$ cells $/ \mu \mathrm{L}$ who are not responding satisfactorily to long-acting inhaled bronchodilator(s). In addition, data from epidemiological studies and a number of post-hoc analyses of clinical trials have demonstrated that blood eosinophil levels are associated not only with response to ICS but also systemic corticosteroids, and with the risk of exacerbations, mortality and length of hospitalisation. ${ }^{13-17}$ Different pathological mechanisms of COPD, however, may coexist in the same patient. ${ }^{6}$ While guidance including use of the blood eosinophil count is a welcome addition to COPD management, its utility nevertheless continues to garner much debate within the COPD and wider respiratory community.

Two international meetings, facilitated by GlaxoSmithKline plc (online supplemental file A), involving respiratory medicine specialists, immunologists and primary/secondary care physicians, took place in November 2018 and March 2019. The aims were to reappraise available data to encourage scientific debate and discussion around the role of immune cells in the disease

Box 1 COPD poses many diagnostic, prognostic and management challenges

- A heterogeneous disease-with respect to symptoms, physiology, inflammation, extrapulmonary effects, response to treatment and disease trajectory, thus patients have variable responses to treatments.

- Patient phenotypes can change during the course of COPD.

By the time COPD is diagnosed, the disease is overt and irreversible.

- Many target proteins along the underlying biochemical and molecular pathways have yet to be identified.

- The need to standardise blood and sputum eosinophil cut-off levels. 
processes of COPD and as prognostic and diagnostic biomarkers, and to identify areas of scientific knowledge that are currently deficient and warrant further research. A significant proportion of the meetings focused on the utility of eosinophil-related biomarkers and the identification of clinical biomarkers relevant for COPD. The potential of such a biomarker was discussed in terms of contribution to the assessment of patients, risk prediction, treatment guidance and assessment of response. ${ }^{18}$ The attendees' views on key topics, contextualised with current literature, are summarised in this review article, with the aim of aiding ongoing research into the disease processes of COPD and the development of biomarkers to aid clinical management.

\section{Development of COPD}

Little is known about the early onset of COPD, nor the potential role of eosinophils in this process. Clearly, it takes decades for the disease to develop. ${ }^{19}$ Exposure to noxious particles/gases (eg, via smoking, household wood burners, fires or environmental pollutants) is the main risk factor for COPD, although host factors (eg, genetic background, abnormal lung development and accelerated ageing) are also known to predispose individuals to COPD. ${ }^{1}$ As only a small fraction of smokers (10\%-20\%) develop COPD ${ }^{20}$ other factors must also be involved; indeed, some life-long non-smokers go on to develop COPD-like pathophysiology. ${ }^{21}$ Poverty is consistently associated with airflow obstruction ${ }^{22}$ and individuals of lower socioeconomic status are more likely to develop COPD. ${ }^{23}$ Asthma and airway hyper-responsiveness (without asthma) are also risk factors for COPD. ${ }^{24}$ The underlying mechanisms of COPD, including the relative contributions of neutrophil-mediated and/or eosinophilmediated inflammation, likely differ dependent on a patient's specific disease subtype.

\section{Genetic background contributing to COPD}

Individuals with hereditary A1ATD or with defects in other single genes, such as that coding for matrix metalloprotease-12 (MMP12), provoke a decline in lung function and/or increased risk for COPD. ${ }^{25} 26$ Smokers and non-smokers with severe A1ATD develop aggressive emphysema, though the process occurs faster in smokers. ${ }^{26}$ A1AT is synthesised in the liver and is important as a circulating antiprotease balancing the actions of proteases. In A1ATD, the activity of neutrophil elastases is no longer tightly controlled due to the deficiency of antiproteases, resulting in destruction of elastin in the lung tissue, a process associated with the development of emphysema; acute infection also tends to provoke abnormal processes in A1AT glycosylation. ${ }^{26}$

\section{Emphysema in COPD}

Emphysema is characterised by enlargement of airspace beyond the terminal bronchioles as a result of airway wall destruction. ${ }^{27}$ Centrilobular emphysema is mostly associated with smoking while panlobular emphysema is associated with A1ATD. ${ }^{27} 28$ Emphysema pathogenesis may be provoked by infection and it responds poorly to anti-inflammatory agents. ${ }^{4}$

\section{Bronchitis in COPD}

Overproduction and hypersecretion of mucus by goblet cells, and its reduced elimination, are the primary mechanisms responsible for excessive mucus in chronic bronchitis; however, its precise contribution to the airflow limitation in COPD is still uncertain. ${ }^{27}$ While alveolar pathology is dominant in emphysema, in bronchitis, damage to the airways is largely caused by chronic inflammation $^{29}$ and is often treated using anti-inflammatory agents (eg, corticosteroids).

\section{Small-airway disease}

Increased airway resistance is principally localised in the small airways of $<2 \mathrm{~mm}$ in internal diameter. In healthy individuals, the small airways have a much larger collective cross-sectional area compared with the central airways so that, physiologically, they contribute approximately $20 \%$ of total airflow resistance. This is the reason why $>80 \%$ of the small airways need to be occluded before there is any demonstrable airflow impairment and why many cigarette smokers develop progressive small airway disease long before airflow obstruction is detected. ${ }^{30} 31$ Small-airway disease results from injury (by factors such as cigarette smoke and viral infection), leading to inflammation, airway remodelling and mucous plugging. ${ }^{28}$

\section{COPD-therapeutic intervention}

Current therapies for COPD are largely ineffective. This partly reflects a failure to appreciate the different pathologies underlying COPD. It has proved difficult to find an effective treatment for emphysema, which tends to be corticosteroid resistant. ${ }^{4}{ }^{32}$ Applying a universal/broad-spectrum treatment to different patient phenotypes or endotypes can cause harm, so identification of treatable traits is desirable, and a precision medicine strategy preferable. Embracing this, the clinical community in COPD is moving away from the 'one size fits all' approach to treatment suggested by prior guidelines. There is an increasing urgency for biomarker targets along the underlying inflammatory pathway, towards the diagnosis of airway disease with a specific inflammatory phenotype or endotype. Perhaps one of the most apt descriptions of a treatable traits approach is that it deconstructs airway disease into its component parts for targeting, including airway eosinophilia, cough reflex hypersensitivity and airway structural damage. ${ }^{33}$ Heaney and McGarvey ${ }^{33}$ comment that some traits are more treatable than others, citing the example that it is easier to target eosinophil dysfunction than it is to treat cough reflex hypersensitivity; nevertheless, novel therapies are emerging all the time.

While noxious stimuli drive the disease in otherwise healthy individuals, ${ }^{27}$ similar exposures can provoke different pulmonary processes in different individuals, implying that certain individuals may be more susceptible to the inciting stimuli than others. Two attractive-but not mutually exclusive-hypotheses have emerged to try and explain the course of disease in COPD: tissue imbalances of proteases/antiproteases and tissue imbalances of oxidants/antioxidants. ${ }^{27}$ The disease processes can occur over many years without the individual suffering any signs or symptoms of COPD ('allostasis').

Allostasis associated with subclinical disease is the key stage at which to identify early and potentially reversible airway damage, and attempt to remove noxious (or other inciting) stimuli. Theoretically, it may also be the point at which treatment could stop the destructive processes and prevent the development of overt COPD, a state which can be coined as 'pathostasis'. ${ }^{27}$ Opinion is clear that the identification of biomarkers in COPD is key to being able to discriminate between 'healthy' smokers and smokers in allostasis. For this to happen, a thorough understanding of the early biochemical and molecular processes of COPD is required. After the point of allostasis, the disease is irreversible, slowly progressive and, crucially, difficult to treat. If no intervention is made at allostasis, the mechanisms underlying the inflammatory responses pass a 'point of no return' and 
even when inciting agents subside (eg, smoking cessation), the inflammation remains. As yet, it is unclear when, where or how the transformation to 'persistent inflammation' occurs, or even whether there is a change in phenotype at this stage; more data are needed to explain these aspects. Specific longitudinal tests to determine the extent to which the immune system is activated may help to predict which patients will go on to develop COPD. Novel therapeutics should be targeted at the different phases of disease.

\section{COPD and biomarkers}

Current consensus is that a reliable, easy-to-measure and clinically relevant biomarker would be invaluable in improving patient outcomes in COPD. The WHO defines a biomarker as: 'any substance, structure or process that can be measured in the body or its products and influence or predict the incidence of outcome or disease'. ${ }^{34}$ Clinical and immunological biomarkers are now beginning to emerge in COPD and asthma, which will help to inform disease prognosis and response to therapy, as well as identify new therapeutic targets. These biomarkers could help to improve targeting of treatments and could identify patients who are likely to respond to novel treatments. ${ }^{33}$

\section{Neutrophilic inflammation in COPD}

Most studies have focused on the underlying neutrophilic inflammation in COPD, and neutrophil activity has been well characterised. ${ }^{35-38}$ Patients with COPD with recurrent infective exacerbations have high rates of bacterial colonisation and neutrophilic inflammation. ${ }^{39}$ Although this does not imply causality, it suggests that neutrophil host defence mechanisms are impaired. This concept is supported by studies showing alterations in neutrophil migration, degranulation and production of reactive oxygen species in cells isolated from patients with COPD. ${ }^{37}$ The role of neutrophils in COPD and airway disease has been much studied and has been reviewed extensively elsewhere. $^{363840}$

\section{Eosinophilic inflammation in COPD}

Recently, it has been recognised that eosinophils may be involved in the inflammatory response in COPD. Under certain circumstances, inflammatory cues promote eosinophil recruitment to the lungs, where secretion of a variety of chemokines (eg, CCL5, CCL11, CCL13), cytokines (eg, interleukin (IL)-2, IL-3, IL-4, IL-5, IL-10, IL-12, IL-13, IL-16, IL-25) and cytotoxic granular products (major basic protein, eosinophil cationic protein, eosinophil peroxidase, eosinophil-derived neurotoxin) contributes to inflammation. ${ }^{41-44}$ As yet, the eosinophilic inflammatory response is not completely understood, though it appears to enhance host defences in allergic disease and may make certain individuals more susceptible to exacerbations. ${ }^{16}$ In the remainder of this article, we highlight relevant clinical studies that support the eosinophil as a potential biomarker, and eosinophilia as a treatable trait.

Eosinophils are inflammatory leucocytes consisting of bi-lobed nuclei and large acidophilic cytoplasmic granules. They are produced in healthy bone marrow from CD34+ myeloid progenitors $^{45}$ and the number of eosinophils generated is typically low, with circulating levels ranging from $1 \%$ to $4 \%$ of the total white blood cell count. ${ }^{46}$ Differentiation from a haematopoietic stem cell into a mature eosinophil is promoted by IL-5, while a role in vivo for granulocyte/macrophage-colony-stimulating factor has been suggested ${ }^{47} 48$ (figure 2). Once mature, eosinophils enter the systemic circulation and mainly migrate to the gastrointestinal

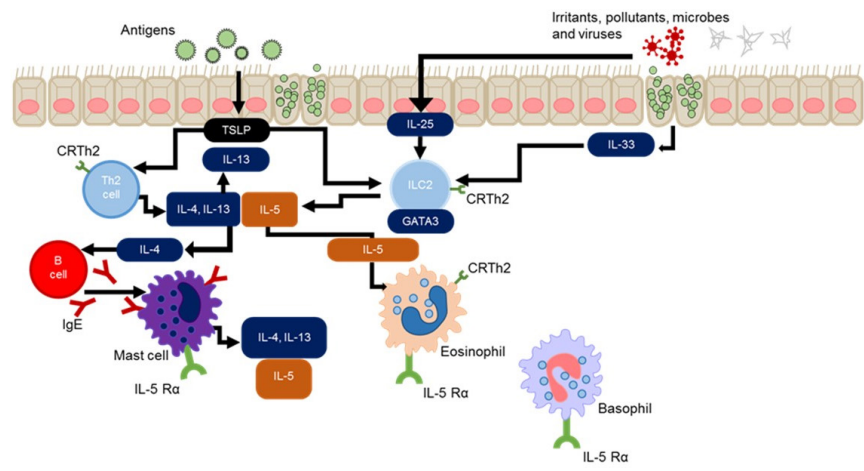

Figure 2 The T2 inflammatory pathway (eosinophilic COPD and asthma) and the target sites for anti-IL-5 agents. Adapted with permission of 2019 Dove Medical Press Limited, from 'Targeting IL-5 in COPD,' by Narendra DK and Hanania Na, Int J COPD 2019;14:104551. ${ }^{11}$. COPD, chronic obstructive pulmonary disease; IL, interleukin.

tract and thymus. ${ }^{46}$ In the context of the inflammatory response, the quality and activation state of eosinophils is likely more important than absolute eosinophil numbers.

Circulating eosinophils are recruited into the airways by immunoregulatory cells and chemokines. ${ }^{49}$ In homeostasis, eosinophils flow along in the blood stream and roll across the bronchial vascular endothelium. Infiltration of eosinophils into the airways only occurs when inflammatory signals induce expression and/or activation of appropriate adhesion molecules on both the bronchial vascular endothelium and epithelium. This recruitment to the airway is under the control of the chemokines CCL5, 7, 11, 13, 15, 24 and 26 and their cognate receptors, such as CCR1, CCR2 and CCR3. ${ }^{50}$ This chemokine/receptor interaction plays a critical role, together with chemoattractant receptor homologous molecule expressed on T helper type 2 cells and its ligand, prostaglandin D2. ${ }^{50}$ Using an in vitro model, Doyle et al $l^{51}$ showed that eosinophil-derived IL-13 promoted alveolar macrophage MMP-12 and that airspace enlargement in a transgenic mouse model was dependent on MMP-12; similarly, in patients with chronic airways disease, pulmonary eosinophilia was associated with elevated MMP-12 levels, predictive of emphysema.

Recent guidance for COPD ${ }^{16}$ refers to the use of eosinophils as a marker of a patient's phenotype and/or predicted responsiveness to ICS. Eosinophil numbers in the blood of patients with COPD and asthma are similar and are predictive of risk of exacerbations and response to ICS during stable disease and to oral corticosteroids during disease exacerbations. ${ }^{52}$ Patients with fixed airflow obstruction often have no response to $\beta$-agonists or corticosteroids. It appears that serum eosinophil counts per se do not provide the sensitivity, specificity or accuracy in the identification of the multiple COPD phenotypes or assist in early diagnosis.

\section{Could enhanced eosinophil numbers be a biomarker of a treatable trait?}

Sputum studies of patients with COPD indicate that eosinophil numbers of $>3 \%$ are found in a subset of patients. ${ }^{53}$ Airway biopsies and sputum samples taken during acute exacerbations of COPD also show an increased number of eosinophils. ${ }^{1154}$

Database studies investigating the role of eosinophils in COPD (including the COPD population in general) can sometimes lead to the surprising conclusion that there is only a weak link between eosinophils and COPD. As the whole COPD population includes not only mild COPD but also patients already 
on an ICS (which will reduce the exacerbation frequency/risk in eosinophilic patients on appropriate treatment), the results of these studies may miss or underestimate the link(s) between COPD and this potential biomarker.

Consensus is that eosinophilic inflammation is a treatable trait in COPD. Asthma and COPD, which were first linked over five decades ago, ${ }^{55}$ are complex, heterogeneous diseases that are increasingly recognised as overlapping syndromes sharing similar pathophysiological mechanisms and treatable traits. ${ }^{56}$ Eosinophilic inflammation in the airways could prove the most treatable trait of COPD. A number of monoclonal antibodies and small molecule therapies have recently been designed to target this inflammatory pathway. For example, there are monoclonal antibodies against IL-5 (eg, mepolizumab), IL-5 receptoralpha (eg, benralizumab), IL-13 (eg, tralokinumab) and IL-4 receptor-alpha (eg, dupilumab). ${ }^{56-59}$ Responses to these agents in COPD have been mixed. Pavord et al $l^{60}$ (online supplemental table 1) investigated mepolizumab in patients with COPD with a history of moderate to severe exacerbations in two randomised controlled trials, one in which patients were stratified by blood eosinophil count (METREX) and one in which all patients had an eosinophilic phenotype (METREO). In patients with an eosinophilic phenotype, the mean annual rate of moderate or severe exacerbations (primary endpoint) was lower with mepolizumab versus placebo in both trials (METREX: rate ratio (RR) $=0.82$; METREO: $R R=0.80(100 \mathrm{mg}), \mathrm{RR}=0.86$ (300 mg); this was statistically significant only in METREX (adjusted $p=0.04$ ). A greater effect of mepolizumab compared with placebo was observed in patients with higher blood eosinophil counts at screening (RR: $0.77 ; 95 \%$ CI, 0.63 to 0.94 ). ${ }^{60}$ These findings suggest that eosinophilic inflammation contributes to exacerbations. ${ }^{60}$ What was challenging in these two trials, however, was that not all patients responded (showed reduced exacerbations) despite similarities in clinical, functional and inflammatory features. Possibly, this could be related to their different endotypes with different underlying processes, which have not yet been identified. Similar results were observed in two randomised controlled trials of benralizumab in patients with COPD who had elevated blood eosinophil counts $(\geq 220$ cells $/ \mu \mathrm{L}$ ) and a history of moderate or severe exacerbations while taking inhaled dual or triple maintenance therapy (GALATHEA (30 $\mathrm{mg}$ and $100 \mathrm{mg}$ ) and TERRANOVA (10 mg, $30 \mathrm{mg}$ and 100 $\mathrm{mg}$ ), online supplemental table 1). In both trials, annualised COPD exacerbation RRs (primary endpoint) were lower with benralizumab versus placebo, but statistical significance was not achieved (GALATHEA: $R R=0.96(p=0.65)$ and $0.83(\mathrm{p}=0.05)$; TERRANOVA: $R R=0.85(p=0.06), 1.04(p=0.66)$ and 0.93 $(p=0.40)) .{ }^{61}$ Although elevated blood eosinophil counts at baseline was a key factor for predicting a greater treatment effect of benralizumab, this characteristic alone was not sufficient to determine treatment effect with antieosinophil therapy. ${ }^{62}$

Please refer to the online supplemental file B for a discussion on the 'Standardisation of measurement of eosinophils'.

\section{Response to corticosteroids}

Blood eosinophil counts are useful for predicting response to ICS and may represent a treatable trait for exacerbation frequency with ICS/LABA in patients with COPD and a history of moderate/severe exacerbations. ${ }^{63-65}$ In other respiratory pathologies, the link between eosinophil levels and corticosteroid response has also been shown. Shim et al ${ }^{66}$ were among the first investigators to show that airway eosinophilia indicated responsiveness to corticosteroids. In a small trial in patients with chronic bronchitis, treated either with prednisolone or placebo, patients with increased levels of eosinophils were more likely to respond to corticosteroids $(\mathrm{p}<0.001) .{ }^{66}$ Since then, this finding has been repeated many times and, generally, applies to patients with airway eosinophils of $>3 \%$ with stable COPD. ${ }^{8}$ Pavord et $a l^{63}$ conducted a post-hoc analysis of three randomised controlled studies each of at least 1 year in duration and found that there was a greater response to ICS/LABA compared with placebo or LAMA, in patients with a pretreatment blood eosinophil level of $\geq 2 \%$ ( $R R=0.75$ and $0.63 ; p=0.006$ and $<0.001)$ compared with those with a level of $<2 \%(R R=0.75$ and $0.63 ; p=0.006$ and $<0.001)$. While these post-hoc analyses used a binary cutoff for eosinophil levels, a recent post-hoc analysis by Bafadhel et $\mathrm{al}^{65}$ (online supplemental table 1) comprising a large dataset from three randomised controlled studies comparing ICS/LABA with LABA in patients with COPD, showed that the eosinophil count is a continuous variable. Moreover, these authors reported a significant treatment effect for ICS $(p=0.015)$ that increased with blood eosinophil counts from $>100$ cells $/ \mu \mathrm{L} .{ }^{65}$ The use of the eosinophil count threshold to aid clinical decision-making regarding ICS treatment is seen in the recent GOLD $2020^{1}$ recommendations, whereby patients with a blood eosinophil count of $>300$ cells $/ \mu \mathrm{L}$ have an improved chance of responding to treatment with ICS. ${ }^{1}$ However, eosinophilic airway inflammation is not always responsive to ICS ${ }^{67}$ Despite ICS therapy, many patients with severe eosinophilic asthma have persistent airway type 2 inflammation. ${ }^{68}$

The ISOLDE study ${ }^{69}$ (online supplemental table 1 ) investigated the rate of decline in forced expiratory volume in one second $\left(\mathrm{FEV}_{1}\right)$ with the use of ICS. As this study took place before widespread usage of LABAs, it is unique in that it analysed the effects of ICS alone, rather than in combination with other inhaled medications. Reanalysis of the core ISOLDE data ${ }^{70}$ showed that use of ICS in patients with higher blood eosinophil counts $(\geq 2 \%)$ was associated with a slower rate of decline in FEV (unusually, however, there appeared to be no impact on exacerbation rate). ${ }^{70}$ This effect is not seen in all studies, however. ${ }^{71}$ Smokers, whether they suffer from asthma or COPD, generally do not respond as well to ICS as non-smokers. However, findings from post-hoc analyses of randomised controlled trials of ICS/ $\mathrm{LABA}^{65}$ and ICS/LABA/LAMA ${ }^{72}$ have shown that the magnitude of response to ICS in smokers, in the context of exacerbation reduction, is greatest in those with higher eosinophil levels. Even in patients with COPD who do not respond to ICS, primary care physicians may be reluctant to stop this medication, possibly reflecting the influence of prior national guidance.

\section{Relation to COPD exacerbations}

Patients with higher blood eosinophil levels during stable disease tend to suffer from more frequent and severe exacerbations. A prospective, single-centre study used blood eosinophil levels to direct systemic steroids during an exacerbation. ${ }^{14}$ Eosinophilic exacerbations were associated with rapid symptomatic recovery and fewer treatment failures than non-eosinophilic exacerbations. ${ }^{14} 73$ By contrast, a low eosinophil count during an exacerbation predicted the risk of worse outcomes. ${ }^{16}{ }^{74}$ In cohort studies of patients hospitalised for exacerbations, blood eosinophil counts of $<50$ cells $/ \mu \mathrm{L}$ were more strongly associated with infection ( $91 \%$ vs $52 \%, \mathrm{p}=0.001)$, distinguished patients with longer median hospital stays (7 vs 4 days, $\mathrm{p}<0.001)$ and were associated with lower 12 -month survival $(82.4 \%$ vs $90.7 \%$, $\mathrm{p}=0.028)$ than patients with an eosinophil count of $>150$ cells/ $\mu \mathrm{L} .{ }^{17}$ 
Many current clinical trial inclusion criteria stipulate that patients must have experienced a prespecified number of exacerbations over a given period of time; by taking into account the level of blood eosinophils, clinicians will have to adopt a completely different approach. Furthermore, some investigators $^{75}$ have found that blood eosinophil levels show significant variability throughout the course of COPD, during both stable periods and acute exacerbations, such that a single measurement may not be a reliable predictor of ICS response.

Please refer to the online supplemental file $\mathrm{C}$ for a discussion on the 'Relationship with infectious disease'

\section{COPD—is eosinophil inflammation ready to be used as a treatable trait?}

The 2020 GOLD report ${ }^{1}$ states: 'A number of recent studies have shown that blood eosinophil counts predict the magnitude of the effect of ICS (added on top of regular maintenance bronchodilator treatment) in preventing future exacerbations.' There is a continuous relationship between blood eosinophil counts and ICS effects; no and/or small effects are observed at lower eosinophil counts, with incrementally increasing effects observed at higher eosinophil counts. ${ }^{1676}$ Blood eosinophil levels have been found to correlate with sputum eosinophils, though to a lesser extent than is seen in patients with asthma. ${ }^{77}$ The SPIROMICS investigation $^{7879}$ (online supplemental table 1) used eosinophil cut-offs $>1.25 \%$ for sputum and 200 cells $/ \mu \mathrm{L}$ for blood as the threshold to categorise high and low eosinophil counts. This allowed prediction of clinical differences between patients, such as response to ICS, positive impact on quality of life, improved lung function and the level of emphysema (greater in patients with sputum eosinophilia), but not total yearly exacerbation rate. This investigation suggested that high concentrations of sputum eosinophils were a better biomarker than high concentrations of blood eosinophils to identify a patient subgroup with more severe disease, more frequent exacerbations, and increased emphysema by quantitative CT. Blood eosinophils alone were not a reliable biomarker for COPD severity or exacerbations, or for sputum eosinophils. ${ }^{80}$ Once the cut-off level for high eosinophil count in sputum was raised to $2 \%$, however, a link with the total number of exacerbations was established. A blood eosinophil count of $>100$ cells $/ \mu \mathrm{L}$ to $>300$ cells $/ \mu \mathrm{L}$ identifies the continuous relationship between eosinophils and ICS; indicating first, patients likely to benefit from ICS treatment, and second, patients with the greatest likelihood of treatment benefit with ICS. ${ }^{66}$ These thresholds, of $>100$ cells $/ \mu \mathrm{L}$ and $>300$ cells $/ \mu \mathrm{L}$, are estimates that can predict treatment benefit with ICS, rather than being considered precise cutoff values. ${ }^{1}$ Also, given the chance of steroid-induced morbidity with continued corticosteroid treatment, the measuring of blood eosinophils would offer simple and useful insights. ${ }^{23}$

The consensus from the meeting attendees was that blood eosinophilia may assist clinicians in making clinical decisions for patients with COPD, including estimating the likelihood of a beneficial response with regard to exacerbation risk and, possibly, the risk of infection, to the addition of ICS to regular bronchodilator treatment. Thus, eosinophils can be used as a biomarker in conjunction with clinical assessment. Notably, based on available data, the COPD Biomarker Qualification Consortium has submitted a letter of intent to the Food and Drug Administration proposing blood eosinophils for qualification as a drug development tool. ${ }^{81}$

\section{CONCLUSIONS}

The potential areas for future research in COPD are large and wide ranging (box 2). There is a drive towards personalised

\section{Box 2 Potential goals of future research in COPD}

- A better understanding of the existence of different phenotypes of COPD and that patients may display more than one phenotype, or that their phenotype may change over time.

- Eosinophil kinetics and activation in the setting of COPD to study intravascular kinetics and the physiological fate, and the stability of eosinophil levels longitudinally.

- Develop/identify methods for achieving white cell count normalisation and restoration of white cell homeostasis rather than inhibition.

- Identification of differences in circulating and/or resident eosinophil levels between patients with COPD, individuals in allostasis and healthy subjects.

- A better understanding of the behaviour, existence and location of different white cell phenotypes and the role they, and their interactions, play in acute exacerbations and stable state COPD.

- Investigation of the interactions between neutrophils and eosinophils, cell surface proteins and their actions in different compartments/tissues.

- Targeting mucus hypersecretion and the effects of IL-5 inhibition (eg, with mepolizumab, benralizumab).

medicine in the treatment of COPD, as with many other diseases. Ultimately, many biomarkers are likely to become available to aid the diagnosis, prognosis and management of patients with COPD. Some evidence exists to support eosinophils as a biomarker of a treatable trait in COPD, though it is still lacking and research is ongoing. Nevertheless, widespread introduction of blood eosinophil count in COPD management would be worthwhile. A unified consensus and a practical, accessible and affordable method of using any biomarker for COPD was thought to be of the utmost importance. Challenges around its utilisation include presenting a clear and pragmatic rationale for biomarker-driven therapy, guidance on ICS withdrawal between primary and secondary care and a lack of financial incentives for its widespread clinical application. It seems likely that, in the near future and based on a clear understanding of the underlying pathogenetic pathways in COPD, clinical biomarkers of treatable traits will be able to guide clinicians in their decisions regarding the most effective treatments for patients with airway diseases.

Acknowledgements The authors gratefully acknowledge Neil Barnes' support during the development of this manuscript. The authors would also like to acknowledge all those who contributed to the content of the manuscript through their discussion and input during the scientific meetings to develop the presented consensus expert view, including Dr Angshu Bhowmik, Professor Paul Corris, Dr Hannah Durrington, Dr Neil Greening, Professor Alberto Papi, Professor lan Pavord, Dr Elizabeth Sapey, Dr Mukesh Singh, Dr Charlotte Summers and Professor Mike Thomas. Editorial support (in the form of editorial suggestions to draft versions of this paper, assembling tables and figures, collating author comments, copyediting, referencing and graphic services) was provided by Deborah Porter, MSc, and Carol Richter, PhD, of Gardiner-Caldwell Communications (Macclesfield, UK) and was funded by GlaxoSmithKline plc. Trademarks are the property of their respective owners.

Contributors All authors contributed to the drafting and/or critical review of the manuscript content and all approved the final version for submission.

Funding This work was supported by GlaxoSmithKline plc.

Competing interests $\mathrm{BD}$ reports previous employment with, and stock/share ownership in, GlaxoSmithKline plc. MB reports grants from AZ, personal fees and non-financial support from AZ, Chiesi and GlaxoSmithKline plc, and other financial activities from AlbusHealth. ADS reports grants, personal fees and other financial 
activities from AstraZeneca, Bayer, GlaxoSmithKline plc, Gilead, Novartis, Pfizer, Teva and Chiesi.

Patient consent for publication Not required.

Provenance and peer review Not commissioned; externally peer reviewed.

Open access This is an open access article distributed in accordance with the Creative Commons Attribution Non Commercial (CC BY-NC 4.0) license, which permits others to distribute, remix, adapt, build upon this work non-commercially, and license their derivative works on different terms, provided the original work is properly cited, appropriate credit is given, any changes made indicated, and the use is non-commercial. See: http://creativecommons.org/licenses/by-nc/4.0/.

\section{ORCID iD}

Mona Bafadhel http://orcid.org/0000-0002-9993-2478

\section{REFERENCES}

1 Global Initiative for Chronic Obstructive Lung Disease. Global strategy for the diagnosis, management, and prevention of chronic obstructive pulmonary disease, 2020. Available: https://goldcopd.org/wp-content/uploads/2019/12/GOLD-2020FINAL-ver1.2-03Dec19_WMV.pdf

2 Izquierdo JL, Cosio BG. The dose of inhaled corticosteroids in patients with COPD: when less is better. Int J Chron Obstruct Pulmon Dis 2018;13:3539-47.

3 Cheng S-L. Blood eosinophils and inhaled corticosteroids in patients with COPD: systematic review and meta-analysis. Int I Chron Obstruct Pulmon Dis 2018:13:2775-84

4 Barnes PJ. Inflammatory endotypes in COPD. Allergy 2019;1:1249-56.

5 Turner AM, Tamasi L, Schleich F, et al. Clinically relevant subgroups in COPD and asthma. Eur Respir Rev 2015;24:283-98.

6 Agustí A, Bel E, Thomas M, et al. Treatable traits: toward precision medicine of chronic airway diseases. Eur Respir J 2016;47:410-9.

7 Pizzichini E, Pizzichini MM, Gibson P, et al. Sputum eosinophilia predicts benefit from prednisone in smokers with chronic obstructive bronchitis. Am J Respir Crit Care Med 1998;158:1511-7

8 Brightling CE, Monteiro W, Ward R, et al. Sputum eosinophilia and short-term response to prednisolone in chronic obstructive pulmonary disease: a randomised controlled trial. Lancet 2000:356:1480-5.

9 Leigh R, Pizzichini MMM, Morris MM, et al. Stable COPD: predicting benefit from high-dose inhaled corticosteroid treatment. Eur Respir J 2006;27:964-71.

10 Singh D, Kolsum U, Brightling CE, et al. Eosinophilic inflammation in COPD: prevalence and clinical characteristics. Eur Respir J 2014;44:1697-700.

11 Narendra DK, Hanania NA. Targeting IL-5 in COPD. Int J Chron Obstruct Pulmon Dis 2019;14:1045-51.

12 Bafadhel M, McCormick M, Saha S, et al. Profiling of sputum inflammatory mediators in asthma and chronic obstructive pulmonary disease. Respiration 2012;83:36-44.

13 Hospers JJ, Schouten JP, Weiss ST, et al. Asthma attacks with eosinophilia predict mortality from chronic obstructive pulmonary disease in a general population sample. Am J Respir Crit Care Med 1999;160:1869-74.

14 Bafadhel M, McKenna S, Terry S, et al. Blood eosinophils to direct corticosteroid treatment of exacerbations of chronic obstructive pulmonary disease: a randomized placebo-controlled trial. Am J Respir Crit Care Med 2012;186:48-55.

15 Vedel-Krogh S, Nielsen SF, Lange P, et al. Blood eosinophils and exacerbations in chronic obstructive pulmonary disease. The Copenhagen General Population Study. Am J Respir Crit Care Med 2016:193:965-74.

16 Bafadhel M, Pavord ID, Russell REK. Eosinophils in COPD: just another biomarker? Lancet Respir Med 2017;5:747-59.

17 MacDonald MI, Osadnik CR, Bulfin L, et al. Low and high blood eosinophil counts as biomarkers in hospitalized acute exacerbations of COPD. Chest 2019:156:92-100.

18 Gonçalves I, Guimarães MJ, van Zeller M, et al. Clinical and molecular markers in COPD. Pulmonology 2018;24:250-9.

19 Løkke A, Lange P, Scharling H, et al. Developing COPD: a 25 year follow up study of the general population. Thorax 2006;61:935-9.

20 Siafakas NM, Nikos S. "In the beginning" of COPD: is evolution important? Am J Respir Crit Care Med 2007; 175:423-4.

21 Lamprecht B, McBurnie MA, Vollmer WM, et al. COPD in never smokers: results from the population-based burden of obstructive lung disease study. Chest 2011:139:752-63.

22 Townend J, Minelli C, Mortimer K, et al. The association between chronic airflow obstruction and poverty in 12 sites of the multinational BOLD study. Eur Respir $J$ 2017;49. doi:10.1183/13993003.01880-2016. [Epub ahead of print: 01 Jun 2017].

23 Beran D, Zar HJ, Perrin C, et al. Burden of asthma and chronic obstructive pulmonary disease and access to essential medicines in low-income and middle-income countries. Lancet Respir Med 2015;3:159-70.

24 Silva GE, Sherrill DL, Guerra S, et al. Asthma as a risk factor for COPD in a longitudinal study. Chest 2004;126:59-65.

25 Hunninghake GM, Cho MH, Tesfaigzi Y, et al. MMP12, lung function, and COPD in high-risk populations. N Engl J Med 2009;361:2599-608.
26 Dunlea DM, Fee LT, McEnery T, et al. The impact of alpha-1 antitrypsin augmentation therapy on neutrophil-driven respiratory disease in deficient individuals. J Inflamm Res 2018;11:123-34

27 MacNee W. Pathogenesis of chronic obstructive pulmonary disease. Proc Am Thorac Soc 2005;2:258-66.

28 Higham A, Quinn AM, Cançado JED, et al. The pathology of small airways disease in COPD: historical aspects and future directions. Respir Res 2019;20:49.

29 Barnes PJ, Celli BR. Systemic manifestations and comorbidities of COPD. Eur Respir J 2009;33:1165-85.

30 Caramori G, Casolari P, Barczyk A, et al. COPD immunopathology. Semin Immunopathol 2016;38:497-515.

31 Woodruff PG, Barr RG, Bleecker E, et al. Clinical significance of symptoms in smokers with preserved pulmonary function. N Engl I Med 2016;374:1811-21.

32 Barnes PJ, Adcock IM. Glucocorticoid resistance in inflammatory diseases. Lancet 2009:373:1905-17.

33 Heaney LG, McGarvey LPA. Personalised medicine for asthma and chronic obstructive pulmonary disease. Respiration 2017;93:153-61.

34 World Health Organisation. WHO international programme on chemical safety. Biomarkers in risk assessment: validity and validation, 2001. Available: http://www. inchem.org/documents/ehc/ehc/ehc222.htm

35 Carter RI, Mumford RA, Treonze KM, et al. The fibrinogen cleavage product $\mathrm{A} \alpha$-Val360, a specific marker of neutrophil elastase activity in vivo. Thorax 2011;66:686-91.

36 Liu J, Pang Z, Wang G, et al. Advanced role of neutrophils in common respiratory diseases. J Immunol Res 2017;2017:1-21.

37 Wang Y, Xu J, Meng Y, et al. Role of inflammatory cells in airway remodeling in COPD. Int J Chron Obstruct Pulmon Dis 2018;13:3341-8.

38 Jasper AE, Mclver WJ, Sapey E, et al. Understanding the role of neutrophils in chronic inflammatory airway disease. F1000Res 2019;8:557.

39 Sapey E, Stockley RA. COPD exacerbations . 2: aetiology. Thorax 2006;61:250-8.

40 Hoenderdos $\mathrm{K}$, Condliffe A. The neutrophil in chronic obstructive pulmonary disease. Am J Respir Cell Mol Biol 2013;48:531-9.

41 Mogbel R, Levi-Schaffer F, Kay AB. Cytokine generation by eosinophils. J Allergy Clin Immunol 1994;94:1183-8.

42 Davoine F, Lacy P. Eosinophil cytokines, chemokines, and growth factors: emerging roles in immunity. Front Immunol 2014;5:570.

43 George L, Brightling CE. Eosinophilic airway inflammation: role in asthma and chronic obstructive pulmonary disease. Ther Adv Chronic Dis 2016;7:34-51.

44 Tashkin DP. Wechsler ME. Role of eosinophils in airway inflammation of chronic obstructive pulmonary disease. Int I Chron Obstruct Pulmon Dis 2018;13:335-49.

45 Hassani M, van Staveren S, van Grinsven E, et al. Characterization of the phenotype of human eosinophils and their progenitors in the bone marrow of healthy individuals. Haematologica 2020;105:e52-6.

46 Camp J, Cane JL, Bafadhel M. Shall we focus on the eosinophil to guide treatment with systemic corticosteroids during acute exacerbations of COPD?: PRO. Med Sci 2018;6:74

47 Hercus TR, Cambareri B, Dottore M, et al. Identification of residues in the first and fourth helices of human granulocyte-macrophage colony-stimulating factor involved in biologic activity and in binding to the alpha- and beta-chains of its receptor. Blood 1994:83:3500-8

48 Low EV, Hughes SM, Zaffarullah S, et al. ICS use may modify FEV1 decline in $\alpha 1$-antitrypsin deficiency patients with relatively high blood eosinophils. Respiration 2018:95:114-21.

49 Smit JJ, Lukacs NW. A closer look at chemokines and their role in asthmatic responses. Eur J Pharmacol 2006;533:277-88

50 Hirai H, Tanaka K, Yoshie O, et al. Prostaglandin D2 selectively induces chemotaxis in Thelper type 2 cells, eosinophils, and basophils via seven-transmembrane receptor CRTH2.J Exp Med 2001:193:255-62.

51 Doyle AD, Mukherjee M, LeSuer WE, et al. Eosinophil-derived IL-13 promotes emphysema. Eur Respir J 2019;53. doi:10.1183/13993003.01291-2018. [Epub ahead of print: 30 May 2019].

52 National Institute for Health and Care Excellence. Chronic obstructive pulmonary disease in over 16s: diagnosis and management NICE guideline [NG115], 2018. Available: https://www.nice.org.uk/guidance/ng115

53 Saha S, Brightling CE. Eosinophilic airway inflammation in COPD. Int I Chron Obstruct Pulmon Dis 2006;1:39-47.

54 Siva R, Green RH, Brightling CE, et al. Eosinophilic airway inflammation and exacerbations of COPD: a randomised controlled trial. Eur Respir I 2007;29:906-13.

55 Orie NG. Correlations of emphysema and asthmatic constitution. Acta Allergol 1961;16:407-9.

56 Bel EH, Ten Brinke A. New anti-eosinophil drugs for asthma and COPD: targeting the trait! Chest 2017;152:1276-82.

57 Brightling CE, Chanez P, Leigh R, et al. Efficacy and safety of tralokinumab in patients with severe uncontrolled asthma: a randomised, double-blind, placebo-controlled, phase 2B trial. Lancet Respir Med 2015;3:692-701.

58 Feng $\mathrm{H}-\mathrm{R}$, Zhang C, Ying S-M. Classical and emerging therapies against chronic obstructive pulmonary disease. Chin Med J 2018;131:1894-7. 
59 Markham A. Benralizumab: first global approval. Drugs 2018;78:505-11.

60 Pavord ID, Chanez P, Criner GJ, et al. Mepolizumab for eosinophilic chronic obstructive pulmonary disease. N Engl I Med 2017;377:1613-29.

61 Criner GJ, Celli BR, Brightling CE, et al. Benralizumab for the prevention of COPD exacerbations. N Engl J Med 2019;381:1023-34.

62 Criner GJ, Celli BR, Singh D, et al. Predicting response to benralizumab in chronic obstructive pulmonary disease: analyses of GALATHEA and TERRANOVA studies. Lancet Respir Med 2020;8:158-70.

63 Pavord ID, Lettis S, Locantore N, et al. Blood eosinophils and inhaled corticosteroid/ long-acting $\beta$-2 agonist efficacy in COPD. Thorax 2016;71:118-25.

64 Siddiqui SH, Guasconi A, Vestbo J, et al. Blood eosinophils: a biomarker of response to extrafine beclomethasone/formoterol in chronic obstructive pulmonary disease. Am J Respir Crit Care Med 2015;192:523-5.

65 Bafadhel M, Peterson S, De Blas MA, et al. Predictors of exacerbation risk and response to budesonide in patients with chronic obstructive pulmonary disease: a post-hoc analysis of three randomised trials. Lancet Respir Med 2018;6:117-26.

66 Shim C, Stover DE, Williams Jr MH. Response to corticosteroids in chronic bronchitis. J Allergy Clin Immunol 1978:62:363-7.

67 Woodruff PG, Modrek B, Choy DF, et al. T-helper type 2-driven inflammation defines major subphenotypes of asthma. Am J Respir Crit Care Med 2009;180:388-95.

68 Peters MC, Kerr S, Dunican EM, et al. Refractory airway type 2 inflammation in a large subgroup of asthmatic patients treated with inhaled corticosteroids. J Allergy Clin Immunol 2019:143:104-13.

69 Burge PS, Calverley PM, Jones PW, et al. Randomised, double blind, placebo controlled study of fluticasone propionate in patients with moderate to severe chronic obstructive pulmonary disease: the ISOLDE trial. BMJ 2000;320:1297-303.

70 Barnes NC, Sharma R, Lettis $\mathrm{S}$, et al. Blood eosinophils as a marker of response to inhaled corticosteroids in COPD. Eur Respir J 2016;47:1374-82.

71 Whittaker HR, Müllerova H, Jarvis D, et al. Inhaled corticosteroids, blood eosinophils, and FEV decline in patients with COPD in a large UK primary health care setting. Int J Chron Obstruct Pulmon Dis 2019:14:1063-73.

72 Pascoe S, Barnes N, Brusselle G, et al. Blood eosinophils and treatment response with triple and dual combination therapy in chronic obstructive pulmonary disease: analysis of the IMPACT trial. Lancet Respir Med 2019;7:745-56.
73 Bafadhel M, Greening NJ, Harvey-Dunstan TC, et al. Blood eosinophils and outcomes in severe hospitalized exacerbations of COPD. Chest 2016:150:320-8.

74 Holland M, Alkhalil M, Chandromouli S, et al. Eosinopenia as a marker of mortality and length of stay in patients admitted with exacerbations of chronic obstructive pulmonary disease. Respirology 2010;15:165-7.

75 Schumann DM, Tamm M, Kostikas K, et al. Stability of the blood eosinophilic phenotype in stable and exacerbated COPD. Chest 2019;156:456-65.

76 Bafadhel M. Eosinophils in COPD: are we nearly there yet? Lancet Respir Med 2017:5:913-4.

77 Pignatti P, Visca D, Cherubino F, et al. Do blood eosinophils strictly reflect airway inflammation in COPD? Comparison with asthmatic patients. Respir Res 2019:20:145.

78 Couper D, LaVange LM, Han M, et al. Design of the subpopulations and intermediate outcomes in COPD study (SPIROMICS). Thorax 2014;69:492-5.

79 Hastie AT, Martinez FJ, Curtis JL, et al. Association of sputum and blood eosinophil concentrations with clinical measures of COPD severity: an analysis of the SPIROMICS cohort. Lancet Respir Med 2017:5:956-67.

80 Kostikas K, Brindicci C, Patalano F. Blood eosinophils as biomarkers to drive treatment choices in asthma and COPD. Curr Drug Targets 2018;19:1882-96.

81 Food and Drug Administration. DDT \#000057 BQP qualification program cover letter - FDA, 2019. Available: https://www.fda.gov/media/130245/download

82 Agustí A, Bafadhel M, Beasley R, et al. Precision medicine in airway diseases: moving to clinical practice. Eur Respir J 2017;50. doi:10.1183/13993003.01655-2017

83 König IR, Fuchs O, Hansen G, et al. What is precision medicine? Eur Respir J 2017;50. doi:10.1183/13993003.00391-2017

84 Hofmann-Apitius M, Alarcón-Riquelme ME, Chamberlain C, et al. Towards the taxonomy of human disease. Nat Rev Drug Discov 2015;14:75-6.

85 Vrijheid M. The exposome: a new paradigm to study the impact of environment on health. Thorax 2014;69:876-8.

86 Wild CP. The exposome: from concept to utility. Int J Epidemiol 2012;41:24-32.

87 Agustí A, Celli B, Faner R. What does endotyping mean for treatment in chronic obstructive pulmonary disease? Lancet 2017;390:980-7.

88 Anderson GP. Endotyping asthma: new insights into key pathogenic mechanisms in a complex, heterogeneous disease. Lancet 2008;372:1107-19.

89 Jones PW, Agusti AGN. Outcomes and markers in the assessment of chronic obstructive pulmonary disease. Eur Respir J 2006;27:822-32. 